\title{
Nitrite oxidizing bacteria (NOB) contained in influent deteriorate mainstream NOB suppression
} by sidestream inactivation

Haoran Duan ${ }^{\mathrm{a}, \mathrm{b}}$, Liu Ye ${ }^{\mathrm{b}}$, Qilin Wang ${ }^{\mathrm{a}, \mathrm{c}}$, Min Zheng ${ }^{\mathrm{a}, \mathrm{d}}$, Xuanyu Lu ${ }^{\mathrm{a}, \mathrm{b}}$, Zhiyao Wang ${ }^{\mathrm{a}}$, Zhiguo Yuan, ${ }^{\mathrm{a}, *}$

aAdvanced Water Management Centre, The University of Queensland, St Lucia, QLD 4072, Australia

${ }^{b}$ School of Chemical Engineering, The University of Queensland, St. Lucia, QLD 4072, Australia

${ }^{\circ}$ Centre for Technology in Water and Wastewater, School of Civil and Environmental Engineering, University of Technology Sydney, Sydney, NSW 2007, Australia

${ }^{\mathrm{d}}$ State Key Joint Laboratory of Environment Simulation and Pollution Control, School of Environment, Tsinghua University, Beijing 100084, China

*Corresponding author: Tel.: +61 73365 4726; fax: +61 733654726.

E-mail address: zhiguo@awmc.uq.edu.au (Z. Yuan).

\section{Graphical Abstract}

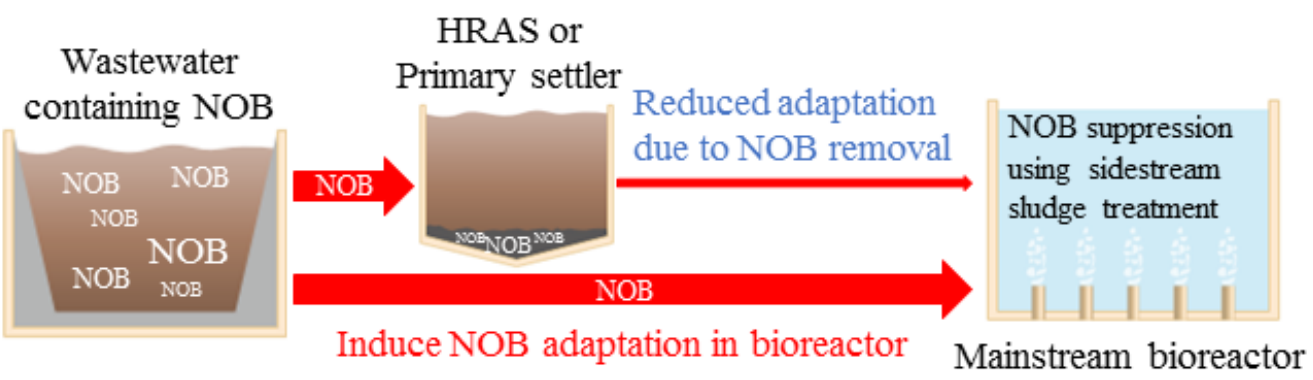

\begin{abstract}
Sidestream sludge treatment approaches have been developed in recent years to achieve mainstream nitrite shunt or partial nitritation, where NOB are selectively inactivated by biocidal factors such as free nitrous acid (FNA) or free ammonium (FA) in a sidestream reactor. The existence of NOB in raw wastewater has been increasingly realized and could pose critical challenge to stable NOB suppressions in those systems. This study, for the first time, evaluated
\end{abstract}


the impact of influent NOB on the NOB suppressions in a mainstream nitrite shunt system achieved through sidestream sludge treatment. An over 500-day sequential batch reactor operation with six experimental phases rigorously demonstrated the negative effects of influent NOB on mainstream NOB control. Continuously seeding of NOB contained in influent stimulated NOB community shifts, leading to different extents of ineffective NOB suppression. The role of primary wastewater treatment in NOB removal from raw wastewater was also investigated. Results suggest primary settling and High Rate Activated Sludge system could remove a large part of NOB contained in raw wastewater. Primary treatment for raw wastewater is necessary for ensuring stable mainstream NOB suppressions.

Keywords: $N O B$, nitrite shunt, wastewater, suppression, adaptation, mainstream 


\section{Introduction}

The nitrite shunt and the partial nitritation and anammox (PN/A, also named deammonification) are two novel nitrogen removal processes that are more carbon- and energy-efficient than the conventional nitrification/denitrification process $\left(\mathrm{NH}_{4}{ }^{+} \rightarrow \mathrm{NO}_{3}{ }^{-} \rightarrow \mathrm{N}_{2}\right)$ (Cao et al. 2017, Kartal et al. 2010, Peng and Zhu 2006). With nitrite being the intermediate, the nitrite shunt process $\left(\mathrm{NH}_{4}{ }^{+} \rightarrow \mathrm{NO}_{2}{ }^{-} \rightarrow \mathrm{N}_{2}\right)$ reduces the organic carbon demand (COD) for denitrification, oxygen requirement for nitrification, and excess sludge production by $40 \%, 25 \%$ and $33-55 \%$ respectively (Antileo et al. 2013, Turk and Mavinic 1986). The PN/A process, namely, partial nitritation $\left(\mathrm{NH}_{4}{ }^{+} \rightarrow \mathrm{NO}_{2}{ }^{-}\right)$followed by anammox (anaerobic ammonium oxidation, $\mathrm{NH}_{4}^{+}+$ $\mathrm{NO}_{2}{ }^{-} \rightarrow \mathrm{N}_{2}$ ), could further reduce the COD and oxygen demand, and excess sludge production, by nearly $100 \%, 60 \%$ and $80 \%$, respectively (Jetten et al. 1997, Wett 2007). The carbon- and energy-efficient mainstream nitrite shunt or mainstream PN/A process is a promising solution for wastewater treatment plants (WWTPs) to maximize bioenergy recovery while achieving satisfactory nutrient removal.

The key step for the nitrite shunt or PN/A is the stable partial nitrification, which is achieved by the suppression of nitrite oxidizing bacteria ( $\mathrm{NOB}$; $\mathrm{NO}_{2}{ }^{-} \rightarrow \mathrm{NO}_{3}{ }^{-}$) while maintaining the ammonium oxidizing bacteria (AOB; $\mathrm{NH}_{4}{ }^{+} \rightarrow \mathrm{NO}_{2}{ }^{-}$). Due to different physiological characteristics of AOB and NOB, many approaches have been proposed to suppress NOB in wastewater treatment, which can be classified into two categories: mainstream inhibition and sidestream inactivation. The mainstream inhibition approach manipulates the biological reactor conditions to be less favourable for NOB than for AOB, such as restricting the dissolved oxygen (DO) concentration (Ma et al. 2009, Sliekers et al. 2005), controlling the aeration length (Ge et al. 2014, Ma et al. 2017b, Yang et al. 2007), reducing the sludge retention time (SRT) (Blackburne 2006, Yuan and Oleszkiewicz 2011), and maintaining the presence of FNA and/or FA by regulating pH (only applicable to high strength wastewaters) (Vlaeminck et al. 2009). In comparison, the sidestream inactivation approach maintains selective pressure of NOB in a separate, out of mainstream, unit, through which a certain amount of activated sludge from the mainstream biological reactor is passed regularly, before being returned to the mainstream. In this reactor, NOB are inactivated through chemical treatment with, for example, Free Nitrous Acid (FNA, the protonated form of nitrite) (Duan et al. 2018, Wang et al. 2014), Free Ammonia (FA, $\mathrm{NH}_{3}$ ) (Wang et al. 2017), and sulfide (Seuntjens et al. 2018), or through physical treatment such as heat-shock (Chen et al. 2019), and ultrasonic radiation (Zheng et al. 2016, Zheng et al. 
2018). The key underpinning the sidestream approach is the fact that AOB are more resilient to these treatments and are therefore less or even not affected.

Despite a number of approaches proposed, the mainstream nitrite shunt or PN/A has still not been widely applied. One of the major reasons hindering the application is the difficulty of maintaining stable suppression on NOB (Lotti et al. 2015). Most of the recently proposed sidestream sludge treatment approaches were demonstrated in laboratories using synthetic wastewater. Synthetic feed mimicking municipal wastewater has the advantage of maintaining consistent composition thus allowing direct comparison in different phases, and has hence been a preferred option for proof-of-concept studies. One critical difference between synthetic and real wastewater is that microorganisms are typically present in the latter but not in the former. During the transportation of wastewater to WWTPs in sewer pipelines, particularly in gravity sewers, nitrifying bacteria may grow in sewer biofilms, the erosion of which could introduce nitrifiers including NOB to WWTPs (Lemmer et al. 1994). Indeed, the presence of nitrifying bacteria $(\mathrm{AOB}+\mathrm{NOB})$ in raw wastewater reaching WWTPs has been reported (Cébron and Garnier 2005, Jauffur et al. 2014, Yu et al. 2016). The continuous feed of NOB, albeit at a low concentration, could potentially facilitate the development of the NOB community, which may result in unstable NOB suppression in mainstream. However, the impacts of influent NOB on the mainstream NOB suppressions have not been evaluated to date.

In this study, we evaluated the effects of influent NOB on the NOB suppression in a mainstream nitrite shunt system achieved through sidestream sludge treatment. The activities of NOB, the nitrite accumulation ratio (NAR), the nitrogen removal performance, and the microbial communities were monitored and analysed during a long-term laboratory Sequential Batch Reactor (SBR) operation over 500 days. The roles of primary settler and High Rate Activated Sludge (HRAS) processes in removing NOB contained in raw wastewater were also assessed by incubation tests and mathematical modelling.

\section{Material and Methods}

\subsection{Reactor operation and monitoring}

An SBR was set up and operated with a working volume of $8 \mathrm{~L}$ in a temperature-controlled laboratory $\left(22 \pm 1{ }^{\circ} \mathrm{C}\right)$, which is within the typical temperature range of domestic wastewater (Eddy et al. 2013). The SBR was controlled in 6 hour-cyclic mode consisting periods of: anoxic 
feeding (60 min), anoxic reaction (60 $\mathrm{min}$ ), aerobic reaction (180 $\mathrm{min}$ ), sludge wasting (5 min), settling (50 min) and decanting (5 min). The hydraulic retention time (HRT) was controlled at 24 hours by feeding $2 \mathrm{~L}$ of mixed synthetic wastewater and anaerobic digestion liquor into the SBR. Depending on the suspended solids concentration in the effluent, 70 to $110 \mathrm{~mL}$ of the mixed liquor was discharged during the wasting phase of each cycle to maintain a solids retention time (SRT) of approximately 15 days. In periods with FA or FNA treatment, an additional $440 \mathrm{~mL}$ of mixed liquor was removed from the SBR in each cycle, treated for 24 hours as described below, before being returned to SBR. In these periods, the anaerobic digestion liquor was used for sidestream treatment, and was hence fed into the SBR together with the treated sludge, rather than being directly fed to the SBR as in periods without sidestream treatment. A magnetic stirrer $(250 \mathrm{rpm})$ was used to mix sludge in the reactor during reaction phases. DO in the reactor was monitored by a pair of DO meter and probe (TPS, Australia), and maintained in the range $1.5-2.0 \mathrm{mgO}_{2} / \mathrm{L}$ (except for the period with lower DO, as described in section 2.1) by on-off control of the aeration (air flow: 1 LPM). pH was measured by a pair of $\mathrm{pH}$ meter and probe (miniCHEM, Labtek) but not controlled, which varied between 7.2 and 7.4 over a typical cycle.

Sidestream sludge treatment was performed in the sludge treatment unit. Mixed liquor of around $1760 \mathrm{~mL}$ removed from the SBR over one day (i.e. 4 cycles) was thickened to $100 \mathrm{~mL}$. The thickened sludge was transferred into the sludge treatment unit, and treated with FNA or FA for 24 hours (to be further described in Section 2.2). A magnetic stirrer (250 rpm) was used to allow sufficient mixing in the treatment unit. The treatment unit was equipped with a set of $\mathrm{pH}$ meter and probe (miniCHEM, Labtek) connected with PLC for maintaining $\mathrm{pH}$ at its setpoint (see Section 2.2) in the unit by adding $\mathrm{HCl}(1.0 \mathrm{M})$ or $\mathrm{NaOH}(1.0 \mathrm{M})$ via PLC. Following the 24 hours treatment, the treated thickened sludge was recirculated to the SBR equally over four cycles during the feeding stage.

Concentrations of $\mathrm{NH}_{4}{ }^{+}-\mathrm{N}, \mathrm{NO}_{2}^{-}-\mathrm{N}, \mathrm{NO}_{3}{ }^{-}-\mathrm{N}$ in the effluent of the SBR were measured 2-4 times a week. Cycle studies were conducted weekly in the SBR by determining the nitrogen compounds concentrations every $30 \mathrm{~min}$ during one cycle. Mixed liquor suspended solids (MLSS), mixed liquor volatile suspended solids (MLVSS) concentrations and sludge volume index $\left(\mathrm{SVI}_{30}\right)$ were measured weekly to assess the activated sludge property. The activities of AOB and NOB in the SBR were expressed as the biomass-specific ammonium reduction and nitrate production rates, respectively, which were calculated as dividing the volumetric rates 
by the MLVSS concentrations. Batch tests were performed according to Duan et al. (2019) in all phases to determine the activities of NOB after side-stream treatment but prior to being recirculated back to the reactor to assess the effectiveness of side-stream FNA or FA treatment on NOB suppression. Amplicon sequencing was performed for at least three times in each phase of the SBR (see Section 2.2) to monitor the microbial composition. Quality control measures have been taken for the analysis by using MultiQC (version 1.3). To enable a reliable comparison amongst sequencing analyses, normalizations were conducted. $\mathrm{N}_{2} \mathrm{O}$ concentrations in the emission gas of the SBR was measured online during the steady state of each phase (see Supplementary Information for details). The steady state of the SBR was reflected by the comparable and stable sludge concentration and also by the similar $\mathrm{NO}_{3}^{-}-\mathrm{N}, \mathrm{NO}_{2}^{-}-\mathrm{N}^{-}$and $\mathrm{NH}_{4}{ }^{+}-$ $\mathrm{N}$ profiles in operational cycles. Details of methods used for chemical and statistical analysis can be found in Supplementary Information (SI) Section 1.

\subsection{Overall experimental plan}

Six experimental phases were designed to investigate the effects of influent NOB on the mainstream NOB suppression achieved through sidestream sludge treatment. Prior to the start of this study, the reactor was operated with sidestream sludge treatment with FA (Day -125 0), with stable mainstream nitrite shunt achieved (NAR: $91.3 \pm 0.5 \%$ ), as described in Wang et al. (2017). In this phase, the sludge was treated at an FA concentration of $210 \mathrm{mgNH}_{3}-\mathrm{N} / \mathrm{L}$ $\left(\mathrm{NH}_{4}{ }^{+}-\mathrm{N}+\mathrm{NH}_{3}-\mathrm{N}=800 \mathrm{mg} \mathrm{N} / \mathrm{L} ; \mathrm{pH}=8.9 ; \mathrm{T}=22^{\circ} \mathrm{C}\right)$. The treatment ratio was 0.29 , i.e. $29 \%$ of the sludge in the SBR was treated every day. This phase is referred to as Phase 0.

In Phase I (Day 0 - 94), sludge treatment with FA was suspended.

In Phase II (Day 95 - 171), NOB-containing sludge was added to the synthetic feed to achieve an estimated NOB concentration that mimics that in raw wastewater (see Section 2.4 for the determination of NOB in raw wastewater). No sludge treatment was applied in this phase. Phase II aimed to unveil the impact of NOB in influent on an established mainstream nitrite shunt in the absence of sidestream sludge treatment.

In Phase III (Day 172 - 315), sludge treatment with FA was implemented, with the addition of NOB to the influent continued. The FA treatment conditions applied were identical to those in Phase 0 . Effects of influent NOB on establishing and maintaining mainstream nitrite shunt by sidestream sludge treatment were assessed in this phase. 
In Phase IV (Day 316-387), DO level in the SBR was reduced (from 1.5-2.0 $\mathrm{mgO}_{2} / \mathrm{L}$ to 0.4$0.6 \mathrm{mgO}_{2} / \mathrm{L}$ ) to provide an additional selection factor against the NOB community adapted to the FA treatment. The DO level was adjusted back to $1.5-2.0 \mathrm{mgO}_{2} / \mathrm{L}$ from Day 355 onwards due to the ineffectiveness of this method in suppressing NOB.

In Phase V (Day 388-451), the chemical used for side-stream sludge treatment was switched from FA to FNA, an alternating strategy previously demonstrated to be effective in addressing the NOB adaptation issue (Duan et al. 2019). The same FNA treatment conditions were applied $\left(\mathrm{FNA}=3.07 \mathrm{mgN} / \mathrm{L}, \mathrm{NO}_{2}{ }^{-}=400 \mathrm{mgN} / \mathrm{L}, \mathrm{pH}=5.5, \mathrm{~T}=22^{\circ} \mathrm{C}\right.$, and treatment ratio $\left.=0.29\right)$. The effect of influent NOB on mainstream NOB suppression was further assessed in this phase.

In Phase VI (Day 452-520), the continuing NOB addition to the influent was reduced to 5\% of the previous level, to mimic the effluent of a primary settler or HRAS system (see Section 2.3 for the experimental determination of NOB concentrations in these streams). This phase aimed to reveal the role of primary settler and HRAS on the mainstream NOB suppression.

\subsection{Determination of NOB levels in real wastewater}

To understand the levels of influent NOB entering the bioreactor of WWTPs and the role of primary treatment process, NOB concentrations in raw wastewater, primary settler effluent and HRAS effluent were determined by incubation tests and model estimations.

Samples of raw wastewater and primary settler effluent were collected from the Luggage Point Wastewater Treatment Plant (LP WWTP) at Brisbane, Australia. The HRAS effluent samples were taken from a pilot-scale HRAS reactor operated at the LP WWTP receiving the same raw wastewater. The pilot-scale HRAS reactor design and operation is presented in SI Section 2. Wastewater samples were collected simultaneously (within half-hour) at all three sampling locations, on four different days to ensure direct comparison and representativeness. Wastewater samples were used for incubation tests within 4 hours of collection.

Incubation tests were carried out in $250 \mathrm{~mL}$ Erlenmeyer flasks with $100 \mathrm{~mL}$ wastewater samples, in a temperature controlled shaking incubator (INFORS Multitron incubation shaker, Switzerland) operated at $150 \mathrm{rpm}$ and $30^{\circ} \mathrm{C} . \mathrm{NaNO}_{2}$ stock solution $(50 \mathrm{gN} / \mathrm{L})$ was added into 
the wastewater samples, resulting in an initial $\mathrm{NO}_{2}{ }^{-}$concentration of approximately $20 \mathrm{mgN} / \mathrm{L}$. The incubation tests lasted for 15-22 days and the $\mathrm{pH}$ was maintained between 7.2-7.5 by adding $\mathrm{NaHCO}_{3}(1 \mathrm{M})$ on a daily basis. Samples were taken every 1-3 days and filtered through disposable Milipore filters $(0.45 \mathrm{~mm}$ pore size) for ammonium, nitrite and nitrate analysis. DO levels during the incubation were above $4 \mathrm{mgO}_{2} / \mathrm{L}$ at all times, and hence regarded as non-rate limiting.

Based on nitrogen transformations during the incubation, an ammonium and nitrite oxidation model was developed based on the Activated Sludge Model (ASM) (Henze et al. 2000) to estimate the concentrations of NOB contained in wastewater samples. The model component definitions and stoichiometry, as well as kinetics and parameter values used in the model, are summarized in Table S1 and S2 (SI, Section 3). The parameter estimation was performed in two steps. Concentrations and maximum specific growth rate of $\mathrm{AOB}\left(\mathrm{X}_{\mathrm{AOB}} \& \mu_{\max , \mathrm{AOB}}\right)$ were firstly evaluated based on the ammonium and $\mathrm{NO}_{\mathrm{x}}{ }^{-}\left(\mathrm{NO}_{2}{ }^{-}+\mathrm{NO}_{3}{ }^{-}\right)$concentration data, and followed by the estimation of concentrations and maximum specific growth rate of $\mathrm{NOB}\left(\mathrm{X}_{\mathrm{NOB}}\right.$ $\left.\& \mu_{\max , \mathrm{NOB}}\right)$ based on the nitrite and nitrate concentration data. For each type of wastewater, targeted parameters were evaluated using results from four sets of incubation tests (wastewater collected on four different days). Parameter estimation and uncertainty evaluation were carried out in accordance with Batstone et al. (2003).

To validate the estimation method, additional incubation tests were carried out with diluted wastewater samples. The wastewater was diluted from one of the wastewater samples collected for the incubation test that used for parameter estimation. The wastewater samples were diluted two and four times by adding synthetic wastewater that contains no biomass (same as the synthetic feed to the SBR, Section 2.4) to regulate the initial amount of $\mathrm{AOB}$ and $\mathrm{NOB}\left(\mathrm{X}_{\mathrm{AOB}} / 2\right.$, $\mathrm{X}_{\mathrm{NOB}} / 2$ and $\left.\mathrm{X}_{\mathrm{AOB}} / 4, \mathrm{X}_{\mathrm{NOB}} / 4\right)$. As $\mathrm{X}_{\mathrm{AOB}}, \mathrm{X}_{\mathrm{NOB}}, \mu_{\max , \mathrm{AOB}}$ and $\mu_{\max , \mathrm{NOB}}$ have been obtained from the model estimation, $\mathrm{X}_{\mathrm{AOB}} / 2, \mathrm{X}_{\mathrm{NOB}} / 2$ and $\mathrm{X}_{\mathrm{AOB}} / 4, \mathrm{X}_{\mathrm{NOB}} / 4$ were used as initial concentrations of $\mathrm{AOB}$ and NOB for model simulations. For validation, model simulations were compared with the incubation experimental results.

\subsection{Wastewater composition}

In order to ensure consistent influent with NOB concentration as the only varying factor, synthetic wastewater with NOB addition was used in this study to mimic the raw wastewater 
or primary settler/HRAS effluent. Furthermore, to allow direct comparison of this study to previous studies (Duan et al. 2018, Wang et al. 2017), the same synthetic wastewater was used in this study. The synthetic wastewater was prepared with a mixture of synthetic wastewater and synthetic anaerobic digestion liquor, resulting in total Kjeldahl nitrogen (TKN) and chemical oxygen demand (COD) concentrations of $50 \mathrm{mgN} / \mathrm{L}$ and $300 \mathrm{mgCOD} / \mathrm{L}$, respectively. The synthetic wastewater comprised per litre: $153 \mathrm{mg} \mathrm{NH} 4 \mathrm{Cl}\left(40 \mathrm{mg} \mathrm{NH}{ }_{4}^{+}-\mathrm{N}\right), 83 \mathrm{mg}$ milk powder, $61 \mathrm{mg}$ starch, $60 \mathrm{mg}$ sucrose, $29 \mathrm{mg}$ yeast extract, $12 \mathrm{mg}$ peptone, $45 \mathrm{mg} \mathrm{CH}_{3} \mathrm{COONa}$, $14 \mathrm{mg} \mathrm{KH} 2 \mathrm{PO} 4,13 \mathrm{mg} \mathrm{K} 2 \mathrm{HPO} 4,600 \mathrm{mg} \mathrm{NaHCO}$, $2.5 \mathrm{mg} \mathrm{FeSO} \cdot 7 \mathrm{H}_{2} \mathrm{O}, 0.44 \mathrm{mg} \mathrm{CaCl}_{2}, 0.19$ $\mathrm{mg} \mathrm{NaMoO}_{4} \cdot 2 \mathrm{H}_{2} \mathrm{O}, 0.19 \mathrm{mg} \mathrm{MgCl}_{2}, 0.13 \mathrm{mg} \mathrm{CoCl}_{2} \cdot 6 \mathrm{H}_{2} \mathrm{O}, 0.06 \mathrm{mg} \mathrm{ZnCl}_{2}, 0.06 \mathrm{mg}$ $\mathrm{MnCl}_{2} \cdot 4 \mathrm{H}_{2} \mathrm{O}, 0.06 \mathrm{mg} \mathrm{CuSO} 4,0.06 \mathrm{mg} \mathrm{H}_{3} \mathrm{BO}_{3}$ and $0.04 \mathrm{mg} \mathrm{NiCl} \cdot 6 \mathrm{H}_{2} \mathrm{O}$. The synthetic anaerobic digestion liquor was simulated with $\mathrm{NH}_{4} \mathrm{HCO}_{3}$. In the FA-based treatment periods, it was fed to the sludge treatment reactor to support sludge treatment, and then recirculated to the SBR with FA-treated sludge. During the implementation of FNA treatment, the ammonium in the digestion liquor was assumed to be converted into nitrite by sidestream partial nitritation. The converted digestion liquor was simulated with $\mathrm{NaNO}_{2}$ and fed to the treatment reactor for sludge treatment by FNA, and then returned to the SBR with FNA-treated sludge.

Based on results of incubation tests and model estimation, we added waste activated sludge (WAS) to the synthetic feed to simulate the raw wastewater or primary settler/HRAS effluent. The WAS was collected from the LP WWTP and its compositions, namely, heterotrophic bacteria, $\mathrm{AOB}, \mathrm{NOB}$, particulate, organic inert and inorganic inert, were estimated based on mass balance analyses. The mass balance analyses (presented in SI Section 4) suggested the portion of NOB biomass in the WAS of the LP WWTP is approximately $0.4 \%$. The WAS addition, at $20 \mathrm{mgVSS} / \mathrm{L}$, is therefore calculated to produce the same level of NOB in the feed as in the raw wastewater. Detailed calculations are shown in SI Section 4. In experimental phase $\mathrm{V}$, the WAS addition was reduced to $1 \mathrm{mgVSS} / \mathrm{L}$ ( $95 \%$ reduction) to mimic the NOB contained in real primary settler/HRAS effluent. With estimated NOB levels in real wastewater, the NOB seeding intensities in this study are calculated according to Jauffur et al. (2014). The NOB in the influent resulted in a seeding intensity of 7 - $11 \mathrm{mg}$ NOB per day per gram NOB already present (Phase II-V) while the reduced NOB addition in Phase VI led to a much lower seeding intensity of $0.4-0.6 \mathrm{mg}$ NOB per day per gram NOB already present. In addition, the impact of WAS addition on the influent COD is negligible. During Phase II-V, the high-level introduction of WAS only increased the biodegradable COD in the influent by around 3\% (assuming 30\% biodegradation of WAS). 


\section{Results and Discussion}

\subsection{Existence of NOB in raw wastewater and the removal by primary treatments}

The incubation of raw wastewater has led to substantial production of nitrate and consumption of nitrite (Figure 1), which clearly indicated the existence of NOB in raw wastewater. To estimate the level of NOB contained in raw wastewater, the nitrogen conversions during the incubation were evaluated by an ammonium and nitrite oxidation model. The model simulation produced good fits to the experimental results; and the validation of the model was successfully carried out with the incubations of diluted raw wastewater, as shown in Figure 1. The NOB and $\mathrm{AOB}$ concentrations in the raw wastewater collected on different days were therefore determined to be $0.11 \pm 0.02$ and $0.83 \pm 0.04 \mathrm{mgCOD} / \mathrm{L}$, respectively, as summarized in Table 1 .

For many WWTPs, primary treatment is implemented to partially remove organic matters to the raw wastewater. Primary settling is the most widely used primary treatment process while HRAS process is the most promising alternative technology (Jimenez et al. 2015, Sancho et al. 2019). The removal of solids from raw wastewater by primary treatments could result in the decrease of NOB in the wastewater. The role of primary settler and HRAS on the removal of NOB in raw wastewater has not been reported in literature to date. Consequently, the incubation tests and model estimation were performed for the primary settler effluent and the HRAS effluent to evaluate the concentration of NOB (Figure S1\&S2). The results are summarized in Table 1.
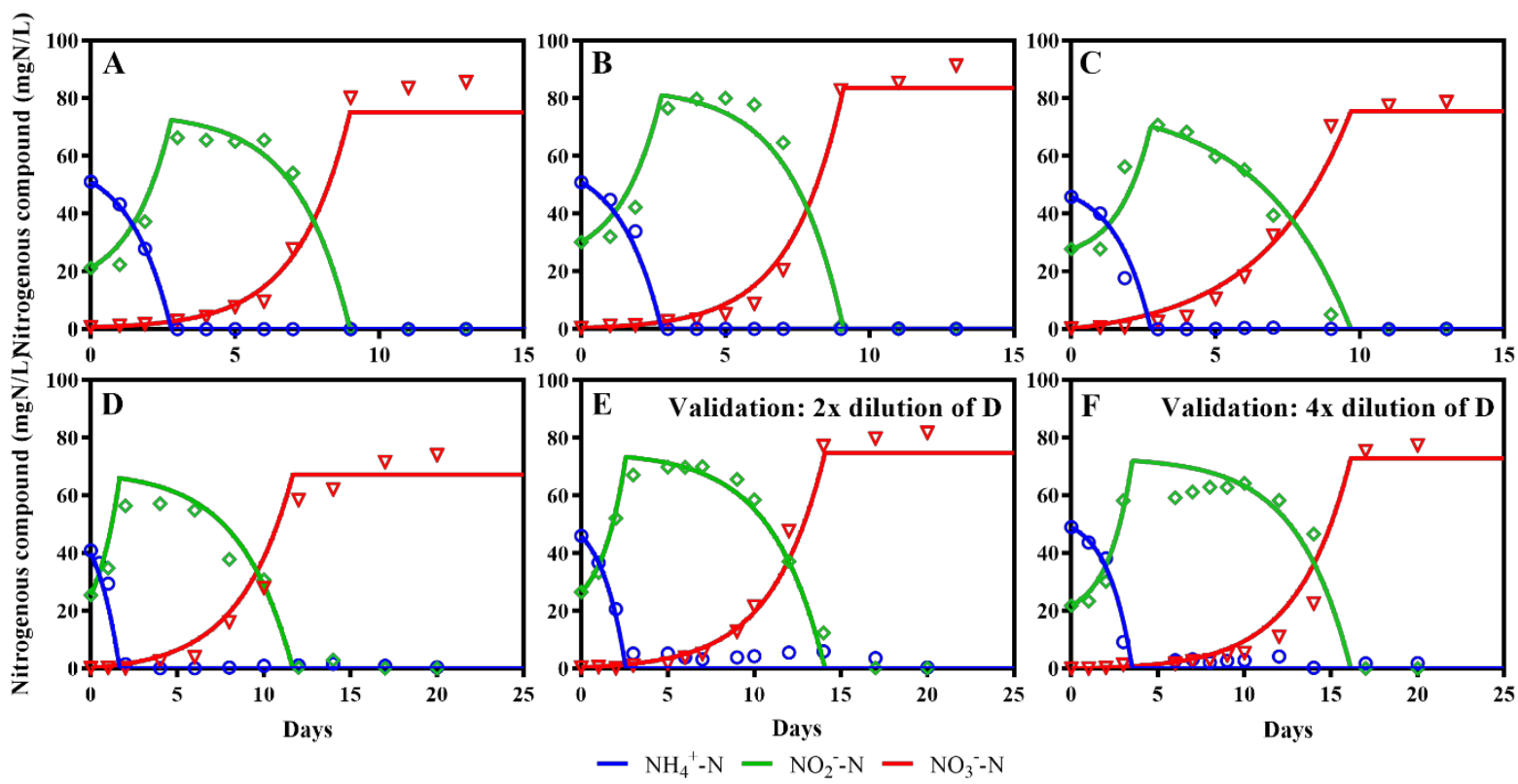
Figure 1. Nitrougenous compound transformations during incubation tests with raw wastewater. A, B, C and D are incubation of raw wastewater collected on four different days; $\mathrm{E}$ and $\mathrm{F}$ are the incubations of 2 and 4 times diluted raw wastewater (from sample D); Experimental results (symbols) and model simulations (lines).

Table 1. Estimated $\mu_{\mathrm{AOB}}, \mu_{\mathrm{NOB}}, \mathrm{X}_{\mathrm{AOB}}, \mathrm{X}_{\mathrm{NOB}}$ based on incubation tests and modelling.

\begin{tabular}{lllllll}
\hline & $\begin{array}{l}\mu_{\mathrm{AOB}}\left(\mathrm{d}^{-1}\right) \\
\mathrm{T}=30^{\circ} \mathrm{C}\end{array}$ & $\begin{array}{l}\mu_{\mathrm{NOB}}\left(\mathrm{d}^{-1}\right) \\
\mathrm{T}=30^{\circ} \mathrm{C}\end{array}$ & $\begin{array}{l}\mathrm{X}_{\mathrm{AOB}} \\
(\mathrm{mgCOD} / \mathrm{L})\end{array}$ & $\begin{array}{l}\mathrm{X}_{\mathrm{NOB}} \\
(\mathrm{mgCOD} / \mathrm{L})\end{array}$ & $\begin{array}{l}\mathrm{AOB} \\
\text { removal } \\
(\%)\end{array}$ & $\begin{array}{l}\text { NOB } \\
\text { removal } \\
(\%)\end{array}$ \\
\hline Raw wastewater & $1.03 \pm 0.27$ & $0.52 \pm 0.03$ & $0.83 \pm 0.04$ & $0.113 \pm 0.021$ & $\mathrm{~N} / \mathrm{A}$ & $\mathrm{N} / \mathrm{A}$ \\
Primary effluent & $0.75 \pm 0.15$ & $0.48 \pm 0.02$ & $0.23 \pm 0.08$ & $0.006 \pm 0.008$ & 72.3 & 94.2 \\
HRAS effluent & $0.75 \pm 0.21$ & $0.55 \pm 0.03$ & $0.32 \pm 0.10$ & $0.010 \pm 0.004$ & 61.4 & 91.0 \\
\hline
\end{tabular}

The primary settler and HRAS studied both exhibited high efficiencies for NOB removal, at $94.2 \%$ and $91.0 \%$, respectively. During the sampling campaign period, the TSS and tCOD removal efficiencies were $55 \pm 9 \%$ and $33 \pm 5 \%(n=5)$ for the sampled primary settler; and 61 $\pm 7 \%$ and $64 \pm 5 \%(n=9)$ for the HRAS $(\mathrm{SRT}=1 \mathrm{~d})$. The removal efficiencies of TSS were comparable between primary settler and HRAS while the HRAS had a higher tCOD removal due to its advantage in soluble COD removal (Nogaj et al. 2015). It should be noted that the TSS removal efficiencies of both the primary settler and HRAS are significantly lower than that for NOB. This can be due to the fact that NOB tend to attach to large flocs in raw wastewater that could be more effectively removed by primary settler or HRAS. Nitrifiers were reportedly able to form strong microcolonies in flocs, which are more resistant to high shear forces (Larsen et al. 2008). NOB were found more resistant from detachment than AOB (Larsen et al. 2008), which might explain the observed higher levels of NOB reductions compared to that of AOB. The efficient removal of particulates/flocs in the primary settler and HRAS reactor therefore lead to effective reduction of NOB in the wastewater.

\subsection{Impact of influent NOB on the mainstream nitrite shunt}

The SBR was operated with sludge treatment by FA with stable mainstream nitrite shunt prior to this study (Day -125-0). As shown in Figure 2, after suspending the sludge treatment from Day 0 , little NOB recovery was observed in the following three months (Phase I). The NAR only marginally decreased from $97.8 \%$ to $82 \%$. The relatively stable NOB suppression was likely a result of a high-level NOB elimination by the sidestream sludge treatment prior to Phase I (Wang et al. 2017). When eliminated to a minimal level, it will likely take a long time 
for NOB to grow back. However, this relative stable NOB suppression could be challenged by the NOB contained in wastewater. Indeed, when NOB supplemented influent was fed to the SBR in Phase II, the nitrite shunt was rapidly interrupted. The NAR decreased to 0 on day 144. In Phase I, the NOB community was dominated by Nitrobacter. The introduction of NOB to the influent during Phase II re-shaped the in-reactor NOB community to Nitrospira-dominant, consistent with that in the feed (Figure 3). This suggested that the NOB community shift was resulted from the NOB seeding with the influent. Results of the two phases illustrated that, the NOB contained in influent could seed the NOB community in the reactor, thus destabilizing NOB suppression.

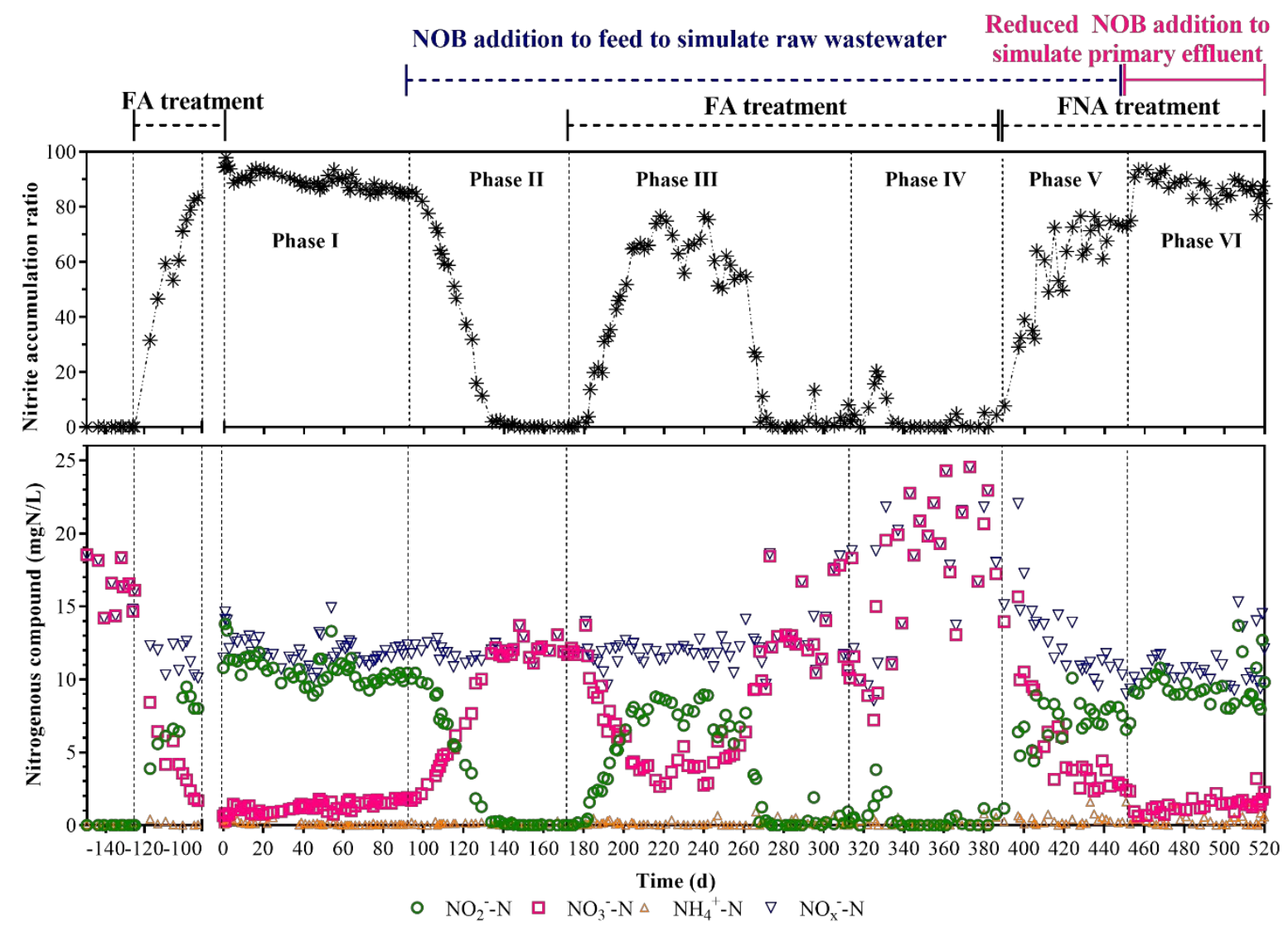

Figure 2. Upper: Nitrite accumulation ratio $\left(\mathrm{NO}_{2}{ }^{-}-\mathrm{N} /\left(\mathrm{NO}_{2}{ }^{-}-\mathrm{N}+\mathrm{NO}_{3}{ }^{-}-\mathrm{N}\right) \times 100 \%\right)$ in the effluent of the SBR ; Lower: Long-term nitrogenous compounds concentrations in the effluent of the SBR; $\mathrm{NO}_{\mathrm{x}}{ }^{-}=\mathrm{NO}_{2}{ }^{-}-\mathrm{N}+\mathrm{NO}_{3}{ }^{-} \mathrm{N}$. Details of data between day $-90-0$ can be found in Wang et al. (2017). 


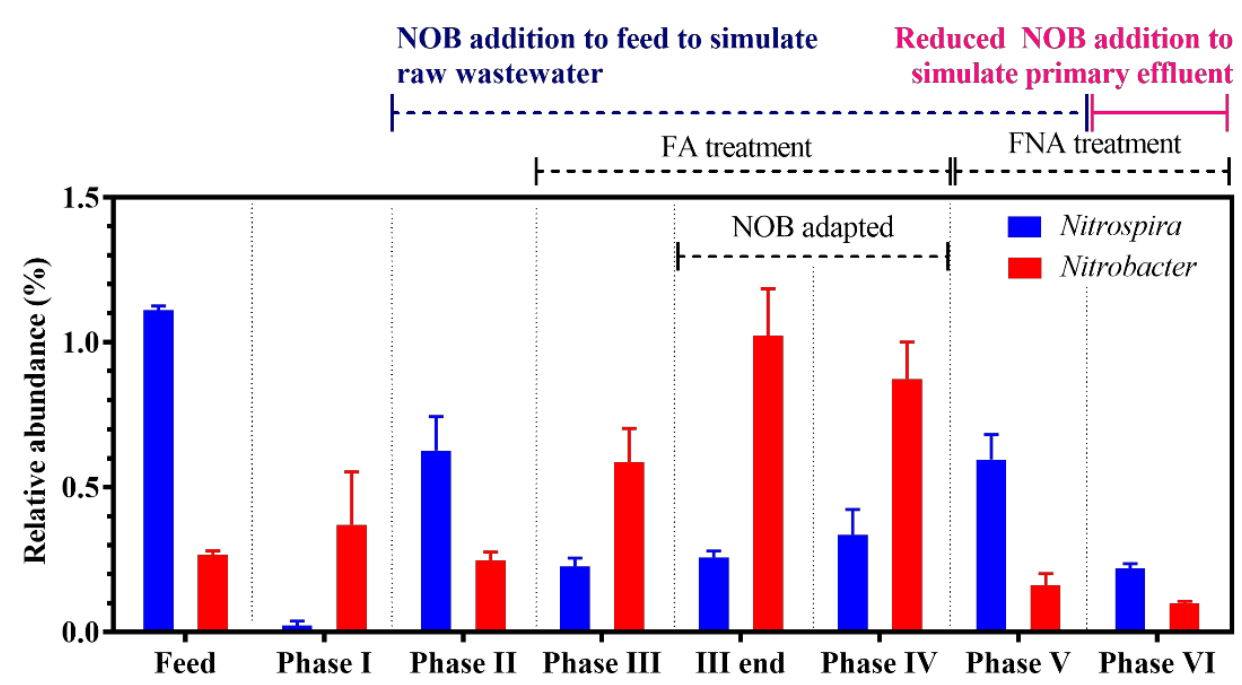

Figure 3. Relative NOB genus abundances (\%). For each experimental phase, biomass samples were taken at steady state; while for Phase III, additional biomass samples were also taken at the end of the experimental phase. Error bars are standard errors in replicate measurements $(\mathrm{n}>=3)$.

Sidestream sludge treatment by FA was re-started in Phase III. Mainstream nitrite shunt was gradually attained and relatively stabilized, with an average NAR of $64.0 \pm 1.9 \%$ during Days 205-265 (approximately 4 SRTs). Compared with the previous study under the same experimental conditions but without NOB in influent (Wang et al. 2017), the NAR level achieved in this period was considerably lower (64\% vs $91 \%)$ and the NOB activity in the reactor was much higher ( $1.2 \pm 0.3$ vs $\left.0.2 \pm 0.1 \mathrm{mgNO}_{3}{ }^{-}-\mathrm{N} / \mathrm{gVSS} / \mathrm{hr}\right)$. Higher tolerance of NOB to FA treatment during this period was also reflected by NOB activities of $0.34 \pm 0.2 \mathrm{mgNO}_{3}^{-}$ $-\mathrm{N} / \mathrm{gVSS} / \mathrm{hr}$ after the FA treatment, in contrast to non-detectable NOB activities in previous study (Wang et al. 2017). It should be noted, compared with NOB activity in the reactor, the NOB activity after treatment reveals a more direct consequence of the treatment. Both higher NOB activities and lower NAR indicated less effective NOB suppression. Furthermore, The NOB community data showed that sludge treatment with FA effectively restrained the growth of Nitrospira while did not significantly affect that of Nitrobacter (Figure 3). It has been reported that Nitrobacter is more likely to develop resistance towards FA treatment (Duan et al. 2019). The consistent introduction of Nitrobacter in the influent might have facilitated the resistance development. Therefore, the influent NOB is likely responsible for the less effective NOB suppression in the system, by directly seeding NOB. 
The developing resistance of NOB to the FA treatment eventually interrupted the NOB suppression and led to failure of the mainstream nitrite shunt in Phase III. The NAR suddenly plummeted, from $54.6 \%$ on day 265 to $0.9 \%$ on day 274 (Figure 2). The adaptation to FA treatment was supported by high $\mathrm{NOB}$ activities of $3.7 \pm 0.4 \mathrm{mgNO}_{3}{ }^{-} \mathrm{N} / \mathrm{gVSS} / \mathrm{hr}$ in the reactor and of $0.9 \pm 0.3 \mathrm{mgNO}_{3}{ }^{-}-\mathrm{N} / \mathrm{gVSS} / \mathrm{hr}$ after treatment. The abundance of Nitrobacter, which is believed to be more resistant to FA treatment increased from $0.6 \pm 0.1$ to $1.0 \pm 0.2 \%$. In comparison, the adaptation of NOB was not observed with a much longer stable nitrite shunt operation ( $>100$ days) in the previous FA treatment study without NOB in the feed (Wang et al. 2017). Being the only difference, the influent NOB very likely accelerated the development of NOB resistance, eventually leading to the collapse of nitrite shunt.

Attempt was made in Phase IV to address the NOB adaptation by limiting the DO. DO level was reduced to $0.4-0.6 \mathrm{mgO}_{2} / \mathrm{L}$ in this phase. NOB was suppressed initially after the reduction, driving the NAR up to $20 \%$ over 5 days (Figure 2). However, NOB quickly acclimated to the reduced DO condition afterwards. Failing to re-establish effective NOB suppression (Figure 2\&3), DO was adjusted back (1.5-2.0 $\left.\mathrm{mgO}_{2} / \mathrm{L}\right)$ from day 355 .

On day 386 (Phase V), the sidestream sludge treatment was alternated from FA-based to FNAbased treatment, a strategy previously demonstrated to be effective in overcoming NOB adaptation (Duan et al. 2019). NAR increased rapidly after implementing the approach, reaching over $70 \%$ on day 410 , and relatively stabilized at $68.8 \pm 2.1 \%$ for the rest of Phase $\mathrm{V}$ (Day 410-455, 3 SRTs). The NOB in-reactor activity decreased to $0.8 \pm 0.1 \mathrm{mgNO}_{3}{ }^{-}-$ $\mathrm{N} / \mathrm{gVSS} / \mathrm{hr}$. The abundance of FA-tolerant Nitrobacter was suppressed to $0.16 \pm 0.04 \%$, which confirmed the effectiveness of the alternate treatment strategy. However, compared with a previous study with the same FNA treatment condition, the suppression on NOB is still less effective, as indicated by higher in-reactor $\mathrm{NOB}$ activities ( 0.8 vs $0.4 \mathrm{mgNO}_{3}{ }^{-}-\mathrm{N} / \mathrm{gVSS} / \mathrm{hr}$ ) and lower NAR (68.8 vs 90.0 \%) (Duan et al. 2018). Nitrospira was believed to be more tolerant to the FNA treatment than Nitrobacter (Duan et al. 2019) and was continuously introduced from the influent. The abundance of Nitrospira in the reactor was indeed promoted in this phase (Figure 3), which could result in the less effective NOB suppression.

In Phase VI, the NOB addition to influent was reduced by $95 \%$ to evaluate the consequences of implementing primary settling. Following the reduction of NOB addition, NAR increased 
instantly, reaching $88.3 \pm 0.8 \%$ (Figure 2). The in-reactor NOB activities decreased simultaneously from $0.8 \pm 0.1$ to $0.5 \pm 0.1 \mathrm{mgNO}_{3}{ }^{-}-\mathrm{N} / \mathrm{gVSS} / \mathrm{hr}$. The abundance of Nitrospira and Nitrobacter also decreased from $0.60 \pm 0.09$ to $0.22 \pm 0.02 \%$ and from $0.16 \pm 0.04$ to 0.10 $\pm 0.01 \%$, respectively, implying effective control of $\mathrm{NOB}$ in this phase. The results further confirmed that the suppression of NOB in this study is strongly correlated to the concentrations of NOB in influent. Moreover, the reactor performance, in terms of NOB suppression, is not significantly different to the previous study using the same FNA sludge treatment but without NOB present $(\mathrm{NAR}=90.0 \pm 0.5 \%, \mathrm{p}>0.05)$ (Duan et al. 2018). The comparable results indicated the negative impact of NOB influent on NOB suppression could be largely prevented by applying primary treatment of raw wastewater, such as primary settling and HRAS.

The over 500 days reactor operation with regulated NOB addition in different experimental phases demonstrated the negative effects of influent NOB on mainstream NOB control. Compared with previous studies using the same feed (no NOB), the same reactor operation and sludge treatment conditions (Duan et al. 2018, Duan et al. 2019, Wang et al. 2017), less effective NOB suppressions were repeatedly observed when NOB were added to the feed in this study (Phase III \& V). As NOB addition level was reduced in Phase VI, the effectiveness of NOB suppression immediately improved, which supported the negative correlation between influent NOB concentrations and NOB suppression. The comparisons with previous studies, and between different phases, all evidently suggested NOB contained in influent deteriorate mainstream NOB suppression achieved through sidestream sludge treatment. In the meantime, as an important by-product of nitrogen removal, $\mathrm{N}_{2} \mathrm{O}$ emissions were monitored during the course of this study. The $\mathrm{N}_{2} \mathrm{O}$ emissions factors varied from $1.7 \%$ to $3.6 \%$, which sit within the reported range of $\mathrm{N}_{2} \mathrm{O}$ emissions from partial nitritation or nitrite shunt systems (Mampaey et al. 2016, $\mathrm{Su}$ et al. 2017). However, no correlation could be established between $\mathrm{N}_{2} \mathrm{O}$ emissions and the amount of NOB added.

Furthermore, NOB community shifts towards Nitrobacter and Nitrospira were observed in Phase III and Phase V, respectively, which could explain the reduced effectiveness of FA or FNA treatments. The community shift patterns observed in this study are consistent with those in previous studies while the shifts progressed much more quickly (Duan et al. 2019). It is likely that the development of community shifts was stimulated by the NOB contained in the influent wastewater. The seeding effects of influent NOB were clearly observed in Phase II (no 
sludge treatment) when the in-reactor NOB community composition was structured according to that in the influent. Therefore, the less effectiveness of FNA or FA treatment on NOB suppression was likely resulted by the stimulated NOB community shifts due to the seeding of NOB from influent.

\subsection{Implication for mainstream nitrite shunt and PN/A}

Current knowledge on mainstream NOB suppression is still evolving. Insufficient understanding of stable NOB suppression is delaying the application of mainstream nitrite shunt or PN/A process, which has been proposed for decades and attracted much attention from industry and academia (Kartal et al. 2010, Peng and Zhu 2006). As mentioned, many approaches have been proposed and demonstrated to control mainstream NOB in lab-scale. However, it is widely recognised that stable NOB suppression is still challenging in larger scales, and remains to be one of the main barriers hindering the up-scale application of such processes (Lotti et al. 2015). An enhanced understanding of NOB suppressions is required for the application of mainstream nitrite shunt and PN/A.

Although the causes of unstable NOB suppression are not yet adequately explored, it is increasingly recognized that NOB adaptation poses a critical challenge to the stable NOB suppression. Community shifts of NOB have been suggested by many studies to cause NOB adaptation. For example, in oxygen-limited conditions, NOB gradually become more efficient in DO utilization than AOB by augmenting the genus Nitrospira (Cao et al. 2018, Liu and Wang 2013). Similarly, Ma et al. (2017a) reported a dominant NOB population shift from Nitrospira to Nitrotoga shortly after the attainment of mainstream nitrite shunt by using FNA treatment, leading to failure of NOB suppression and nitrite shunt. The underlying mechanism of community shifts was that not all NOB populations are equally susceptible to the same suppression, and consequently the less susceptible populations could outcompete others and gradually emerge as the dominating NOB population, leading to ineffective suppression (Duan et al. 2019). It is also possible that certain strains may develop physiological changes to better cope with the suppressing pressure (Huisman and Kolter 1994). Either cases, it was perceived that NOB community shifts occurred spontaneously as some strains of NOB are more tolerant or/and could gradually develop resistance to suppressions. 
While NOB community shifts can occur spontaneously, this study indicates that the progress could be stimulated by external NOB contained in influent wastewater. Results in this study clearly showed that NOB in the influent have accelerated the NOB community shifts, leading to different extents of ineffective NOB suppression. While this study was demonstrated with sidestream sludge treatment approaches, the results could potentially be applicable to other NOB suppression approaches as well. A wide range of NOB lineages are present in raw wastewater, such as Nitrospira, Nitrobacter, Nitrococcus and Nitrospina (Yu et al. 2016). The continuous seeding of a wide range of NOB by the raw wastewater could likely accelerate the NOB community changes, leading to relatively quick adaptations to different kinds of NOB suppressions. The community shifts reported in previous studies carried out with real wastewater (Cao et al. 2018, Ma et al. 2017a), could also be a result of both spontaneous resistance development and external stimulus by NOB in real wastewater. It should be noted that the estimated and investigated level of nitrifiers in raw wastewater in this study $(0.94$ $\mathrm{mgCOD} / \mathrm{L}$ ) is around 5 times lower than that in a previous study in Quebec, Canada (5 $\operatorname{mgCOD} / \mathrm{L}$ ) (Jauffur et al. 2014); and the maximum NOB activity (calculated as $\mu^{*} \mathrm{X}=0.06$ $\mathrm{mgN} / \mathrm{L} / \mathrm{d})$, is much lower than that determined in Xi' an, China (4.3 - $5.3 \mathrm{mgN} / \mathrm{L} / \mathrm{d})$ (Yu et al. 2016). This could be due to differences in the catchment area, sewer systems or experimental determination approaches. A wide range of NOB concentrations measured in real wastewater suggest that the effects of influent NOB could vary significantly in different cases.

Progressed understanding calls for pretreatment of raw wastewater to ensure stable NOB suppression in mainstream nitrite shunt or PN/A. In this regard, primary settler and HRAS systems were demonstrated in this study to be efficient in removing NOB contained in raw wastewater. Indeed, nitrite shunt and PN/A processes are typically conceptualised with the application of primary settling or HRAS to allow upfront separation of organic carbon for bioenergy recovery through anaerobic digestion. However, it is important to note that due to the low influent $\mathrm{COD} / \mathrm{TN}$ ratio, primary settlers have been eliminated in many WWTPs to make more carbon available for nitrogen removal (Wang et al. 2014). Currently, many WWTPs are considering upgrading conventional nitrification/denitrification process to mainstream nitrite shunt, in order to save external carbon supplement and aeration energy. The implementation of primary settler is not considered necessary for the upgrade in the low $\mathrm{COD} / \mathrm{TN}$ case. However, as suggested by this study, primary settler should be implemented for such upgrade to ensure stable mainstream NOB suppressions. 
The limitation of this study should be realized. By using synthetic wastewater with simulated NOB addition, the effects of varying composition in real wastewater, which could influence the stability of NOB suppression, was not assessed. Moreover, while influent NOB have been investigated in this study, other microorganisms in raw wastewater might also have impacts on NOB suppression in the nitrite shunt system. Ultimately, results from this study should be verified with real wastewater.

\section{Conclusions}

In this study, effects of influent NOB on mainstream NOB suppression in a nitrite shunt system achieved by sidestream sludge treatment were investigated through long-term laboratory reactor operations. The levels of NOB in raw wastewater and primary settler, HRAS effluent were evaluated by incubation tests and model estimations. The main conclusions are:

- NOB contained in wastewater could affect the effectiveness of NOB suppression by facilitating NOB resistance to sidestream sludge treatment and potentially to other NOB suppressions, eventually leading to the failure of NOB suppression. The NOB in the influent could stimulate the NOB community shifts in the reactor under NOB suppression pressure to develop resistance.

- Primary settler and HRAS system can efficiently remove NOB contained in raw wastewater, and are necessary for mainstream nitrite shunt or PN/A system.

\section{Acknowledgement}

The research is supported by the Australian Research Council's Linkage Project LP130100361 with City of Gold Coast and Sydney Water Corporation as industry partners. Dr. Haoran Duan thanks Kingsford Environmental (HK) for scholarship support and The University of Queensland for postdoctoral fellowship support. Dr. Liu Ye acknowledges the support of the Australian Research Council (ARC) Discovery Early Career Researcher Award DE150100393. Dr. Qilin Wang acknowledges the support of ARC Discovery Early Career Researcher Award DE160100667. Dr. Min Zheng acknowledges the support of International Postdoctoral Exchange Fellowship Program (China). We thank Ms. Jiaying Li for discussions about sewer biofilm. 


\section{References}

Antileo, C., Medina, H., Bornhardt, C., Muñoz, C., Jaramillo, F. and Proal, J. (2013) Actuators monitoring system for real-time control of nitrification-denitrification via nitrite on long term operation. Chemical Engineering Journal 223, 467-478.

Batstone, D.J., Pind, P.F. and Angelidaki, I. (2003) Kinetics of thermophilic, anaerobic oxidation of straight and branched chain butyrate and valerate. Biotechnology and Bioengineering 84(2), 195-204.

Blackburne, R.J. (2006) Nitrifying bacteria characterisation to identify and implement factors leading to nitrogen removal via nitrite in activated sludge processes. PhD Thesis, The University of Queensland, Brisbane.

Cao, Y., Kwok, B.H., van Loosdrecht, M.C.M., Daigger, G., Png, H.Y., Long, W.Y. and Eng, O.K. (2018) The influence of dissolved oxygen on partial nitritation/anammox performance and microbial community of the $200,000 \mathrm{~m} 3 / \mathrm{d}$ activated sludge process at the Changi water reclamation plant (2011 to 2016). Water Science and Technology 78(3), 634-643.

Cao, Y., van Loosdrecht, M.C.M. and Daigger, G.T. (2017) Mainstream partial nitritationanammox in municipal wastewater treatment: status, bottlenecks, and further studies. Applied Microbiology and Biotechnology 101(4), 1365-1383.

Cébron, A. and Garnier, J. (2005) Nitrobacter and Nitrospira genera as representatives of nitrite-oxidizing bacteria: Detection, quantification and growth along the lower Seine River (France). Water Research 39(20), 4979-4992.

Chen, J., Zhang, S., Han, X., Zhang, L. and Peng, Y. (2019) Nitritation of the real sewage: start-up and maintenance by the side-stream heat-shock treatment. Water Science and Technology.

Duan, H., Wang, Q., Erler, D.V., Ye, L. and Yuan, Z. (2018) Effects of free nitrous acid treatment conditions on the nitrite pathway performance in mainstream wastewater treatment. Science of The Total Environment 644, 360-370.

Duan, H., Ye, L., Lu, X. and Yuan, Z. (2019) Overcoming Nitrite Oxidizing Bacteria Adaptation through Alternating Sludge Treatment with Free Nitrous Acid and Free Ammonia. Environmental Science \& Technology 53(4), 1937-1946.

Eddy, M., Burton, F., Tchobanoglous, G. and Tsuchihashi, R. (2013) Wastewater engineering: treatment and Resource recovery, McGraw-Hill Education: New York, NY, USA. 
Ge, S., Peng, Y., Qiu, S., Zhu, A. and Ren, N. (2014) Complete nitrogen removal from municipal wastewater via partial nitrification by appropriately alternating anoxic/aerobic conditions in a continuous plug-flow step feed process. Water Research 55, 95-105.

Henze, M., Gujer, W., Mino, T. and Van Loosdrecht, M. (2000) Activated sludge models ASM1, ASM2, ASM2d and ASM3, IWA publishing.

Huisman, G.W. and Kolter, R. (1994) Sensing starvation: a homoserine lactone--dependent signaling pathway in Escherichia coli. Science 265(5171), 537.

Jauffur, S., Isazadeh, S. and Frigon, D. (2014) Should activated sludge models consider influent seeding of nitrifiers? Field characterization of nitrifying bacteria. Water Science and Technology 70(9), 1526-1532.

Jetten, M.S.M., Horn, S.J. and van Loosdrecht, M.C.M. (1997) Towards a more sustainable municipal wastewater treatment system. Water Science and Technology 35(9), 171-180.

Jimenez, J., Miller, M., Bott, C., Murthy, S., De Clippeleir, H. and Wett, B. (2015) High-rate activated sludge system for carbon management - Evaluation of crucial process mechanisms and design parameters. Water Research 87, 476-482.

Kartal, B., Kuenen, J.G. and van Loosdrecht, M.C.M. (2010) Sewage Treatment with Anammox. Science 328(5979), 702-703.

Larsen, P., Nielsen, J.L., Svendsen, T.C. and Nielsen, P.H. (2008) Adhesion characteristics of nitrifying bacteria in activated sludge. Water Research 42(10), 2814-2826.

Lemmer, H., Roth, D. and Schade, M. (1994) Population density and enzyme activities of heterotrophic bacteria in sewer biofilms and activated sludge. Water Research 28(6), 13411346.

Liu, G. and Wang, J. (2013) Long-Term Low DO Enriches and Shifts Nitrifier Community in Activated Sludge. Environmental Science \& Technology 47(10), 5109-5117.

Lotti, T., Kleerebezem, R., Hu, Z., Kartal, B., de Kreuk, M.K., van Erp Taalman Kip, C., Kruit, J., Hendrickx, T.L.G. and van Loosdrecht, M.C.M. (2015) Pilot-scale evaluation of anammoxbased mainstream nitrogen removal from municipal wastewater. Environmental Technology 36(9), 1167-1177.

Ma, B., Yang, L., Wang, Q., Yuan, Z., Wang, Y. and Peng, Y. (2017a) Inactivation and adaptation of ammonia-oxidizing bacteria and nitrite-oxidizing bacteria when exposed to free nitrous acid. Bioresource Technology 245, 1266-1270.

Ma, Y., Domingo-Félez, C., Plósz, B.G. and Smets, B.F. (2017b) Intermittent Aeration Suppresses Nitrite-Oxidizing Bacteria in Membrane-Aerated Biofilms: A Model-Based Explanation. Environmental Science \& Technology 51(11), 6146-6155. 
Ma, Y., Peng, Y., Wang, S., Yuan, Z. and Wang, X. (2009) Achieving nitrogen removal via nitrite in a pilot-scale continuous pre-denitrification plant. Water Research 43(3), 563-572.

Mampaey, K.E., De Kreuk, M.K., van Dongen, U.G.J.M., van Loosdrecht, M.C.M. and Volcke, E.I.P. (2016) Identifying N2O formation and emissions from a full-scale partial nitritation reactor. Water Research 88, 575-585.

Nogaj, T., Randall, A., Jimenez, J., Takacs, I., Bott, C., Miller, M., Murthy, S. and Wett, B. (2015) Modeling of organic substrate transformation in the high-rate activated sludge process. Water Science and Technology 71(7), 971-979.

Peng, Y. and Zhu, G. (2006) Biological nitrogen removal with nitrification and denitrification via nitrite pathway. Applied Microbiology and Biotechnology 73(1), 15-26.

Sancho, I., Lopez-Palau, S., Arespacochaga, N. and Cortina, J.L. (2019) New concepts on carbon redirection in wastewater treatment plants: A review. Science of The Total Environment 647, 1373-1384.

Seuntjens, D., Van Tendeloo, M., Chatzigiannidou, I., Carvajal-Arroyo, J., Vandendriessche, S., Vlaeminck, S.E. and Boon, N. (2018) Synergistic exposure of return-sludge to anaerobic starvation, sulfide and free ammonia to suppress nitrite oxidizing bacteria. Environmental Science \& Technology.

Sliekers, A.O., Haaijer, S.C.M., Stafsnes, M.H., Kuenen, J.G. and Jetten, M.S.M. (2005) Competition and coexistence of aerobic ammonium- and nitrite-oxidizing bacteria at low oxygen concentrations. Applied Microbiology and Biotechnology 68(6), 808-817.

Su, Q., Ma, C., Domingo-Félez, C., Kiil, A.S., Thamdrup, B., Jensen, M.M. and Smets, B.F. (2017) Low nitrous oxide production through nitrifier-denitrification in intermittent-feed highrate nitritation reactors. Water Research 123, 429-438.

Turk, O. and Mavinic, D.S. (1986) Preliminary assessment of a shortcut in nitrogen removal from wastewater. Canadian Journal of Civil Engineering 13(6), 600-605.

Vlaeminck, S.E., Terada, A., Smets, B.F., Linden, D.V.d., Boon, N., Verstraete, W. and Carballa, M. (2009) Nitrogen Removal from Digested Black Water by One-Stage Partial Nitritation and Anammox. Environmental Science \& Technology 43(13), 5035-5041.

Wang, Q., Duan, H., Wei, W., Ni, B.-J., Laloo, A. and Yuan, Z. (2017) Achieving Stable Mainstream Nitrogen Removal via the Nitrite Pathway by Sludge Treatment Using Free Ammonia. Environmental Science \& Technology 51(17), 9800-9807.

Wang, Q., Ye, L., Jiang, G., Hu, S. and Yuan, Z. (2014) Side-stream sludge treatment using free nitrous acid selectively eliminates nitrite oxidizing bacteria and achieves the nitrite pathway. Water Research 55, 245-255. 
Wett, B. (2007) Development and implementation of a robust deammonification process. Water Science and Technology 56(7), 81-88.

Yang, Q., Peng, Y., Liu, X., Zeng, W., Mino, T. and Satoh, H. (2007) Nitrogen Removal via Nitrite from Municipal Wastewater at Low Temperatures using Real-Time Control to Optimize Nitrifying Communities. Environmental Science \& Technology 41(23), 8159-8164.

Yu, L.F., Du, Q.Q., Fu, X.T., Zhang, R., Li, W.J. and Peng, D.C. (2016) Community structure and activity analysis of the nitrifiers in raw sewage of wastewater treatment plants.

Yuan, Q. and Oleszkiewicz, J.A. (2011) Low temperature biological phosphorus removal and partial nitrification in a pilot sequencing batch reactor system. Water Science and Technology 63(12), 2802-2807.

Zheng, M., Liu, Y.-C., Xin, J., Zuo, H., Wang, C.-W. and Wu, W.-M. (2016) Ultrasonic Treatment Enhanced Ammonia-Oxidizing Bacterial (AOB) Activity for Nitritation Process. Environmental Science \& Technology 50(2), 864-871.

Zheng, M., Wu, S., Dong, Q., Liu, Y., Huang, X. and Yuan, Z. (2018) Achieving mainstream nitrogen removal via the nitrite pathway from real municipal wastewater using intermittent ultrasonic treatment. Ultrasonics Sonochemistry. 